\title{
How to Write a Textbook in Ten Easy Steps
}

\section{Dr. Barry Dupen, Indiana University Purdue University, Fort Wayne}

Dr. Dupen is an Associate Professor of Mechanical Engineering Technology at Indiana University Purdue University Fort Wayne (IPFW). He has nine years' experience as a metallurgist, materials engineer, and materials laboratory manager in the automotive industry. His primary interests lie in materials engineering, mechanics, and engineering technology education. He is also an experienced contra dance caller. 


\title{
How to Write a Textbook in Ten Easy Steps
}

\begin{abstract}
Strength of Materials is the most difficult course in the first two years of the Mechanical, Civil, and Architectural Engineering Technology programs at Indiana University - Purdue University Fort Wayne (IPFW); consequently it has the highest drop and fail rate. In the past decade, the failure rate in our Strength courses has ranged from 10 to 30\% each semester, under three different professors, using the same algebra-based textbook. Students have trouble using algebra...they prefer to plug numbers into canned equations. The Civil and Architectural students struggle with unit conversions. Although professors provide office hours during the day, most students work on homework in the evening and on weekends, and report that the explanations in the text are insufficient, too wordy, or too difficult to understand at midnight. A root cause of these problems is the editing process; most textbooks are edited for technical content by other professors, so they are technically excellent. However, they are not edited for understandability by the target audience, so many undergraduates find them difficult to understand.

To solve these and other problems, I spent a sabbatical writing a new Strength textbook for Engineering Technology students. Each semester, these students submit editorial changes, for extra credit. Feedback must be both specific and actionable: "this chapter is confusing" does not meet either criterion, whereas "I don't understand how to solve the moment in Example 6, page 45 " meets both criteria. A student may not know what to change, but can easily identify the confusing parts of a text. The book is free, available as a pdf on the course website, and is updated on an ongoing basis.

This paper discusses the writing process, delivery via pdf instead of print, selection of topics requiring extra emphasis, editing assistance from students, and the improvement in learning outcomes. Although the topic of the book was Strength of Materials, this paper discusses techniques that can be applied to a variety of undergraduate engineering textbook topics.

\section{Introduction}

I teach Strength of Materials to Architectural, Civil, and Mechanical Engineering Technology students. Students in the ARET, CET, and MET programs at IPFW must earn a C- or better in Strength in order to pass the course. Table 1 shows the percentage of students needing to repeat Strength due to low grades, along with the repeat rate in all other MET courses. ${ }^{1}$ Based on a $20 \%$ mean repeat rate, Strength is apparently the hardest course in the curriculum. The table does not include students who withdrew from courses because of low grades. When withdrawals are included, the repeat rate in Strength runs between $18 \%$ and $35 \%$.
\end{abstract}


Table 1: Percentage of students in each course who must repeat the course, from Fall 2008 to Fall 2011. Mean values are the total number of students needing to repeat in all semesters divided by the total number of students enrolled in all semesters. A blank cell indicates the course was not offered that semester.

\begin{tabular}{lcccccccc}
\hline Course & F08 & S09 & F09 & S10 & F10 & S11 & F11 & Mean \\
\hline Intro. Engr. Tech. & $3 \%$ & $6 \%$ & $15 \%$ & $16 \%$ & $8 \%$ & $14 \%$ & $8 \%$ & $9 \%$ \\
\hline 2-D CAD & $11 \%$ & $7 \%$ & $11 \%$ & $11 \%$ & $6 \%$ & $13 \%$ & $6 \%$ & $9 \%$ \\
\hline Materials I & $25 \%$ & $16 \%$ & $6 \%$ & $10 \%$ & $16 \%$ & $5 \%$ & $16 \%$ & $12 \%$ \\
\hline Statics & $4 \%$ & $5 \%$ & $20 \%$ & $14 \%$ & $12 \%$ & $9 \%$ & $12 \%$ & $12 \%$ \\
\hline Strength of Materials & $16 \%$ & $10 \%$ & $25 \%$ & $21 \%$ & $25 \%$ & $20 \%$ & $25 \%$ & $20 \%$ \\
\hline Fluid Power & $3 \%$ & & $0 \%$ & & $7 \%$ & & $7 \%$ & $4 \%$ \\
\hline 3-D CAD & & $8 \%$ & $6 \%$ & $12 \%$ & $0 \%$ & $6 \%$ & $0 \%$ & $6 \%$ \\
\hline Machining & $0 \%$ & $0 \%$ & $0 \%$ & $0 \%$ & $6 \%$ & $0 \%$ & $6 \%$ & $2 \%$ \\
\hline Machine Elements & & $0 \%$ & & $3 \%$ & & $0 \%$ & & $1 \%$ \\
\hline Tool Design & $5 \%$ & & $5 \%$ & & $0 \%$ & & $0 \%$ & $3 \%$ \\
\hline Fluid Mechanics & & $4 \%$ & & $0 \%$ & & $0 \%$ & & $1 \%$ \\
\hline Dynamics \& Mechanism & & $0 \%$ & & $0 \%$ & & $0 \%$ & & $0 \%$ \\
\hline Materials II & & $0 \%$ & & $3 \%$ & & $0 \%$ & & $1 \%$ \\
\hline Automatic Systems & $0 \%$ & $0 \%$ & $0 \%$ & $0 \%$ & $0 \%$ & $0 \%$ & $0 \%$ \\
\hline Instrumentation \& Control & $0 \%$ & & & $0 \%$ & & $0 \%$ & $0 \%$ \\
\hline Thermodynamics & $0 \%$ & & $14 \%$ & & $11 \%$ & & $11 \%$ & $10 \%$ \\
\hline Heat Transfer & $0 \%$ & & $0 \%$ & & $0 \%$ & & $0 \%$ \\
\hline Senior Design & $0 \%$ & & $0 \%$ & & $0 \%$ & & $0 \%$ \\
\hline
\end{tabular}

Three different instructors teaching Strength of Materials have had the same general outcome using the same textbook.

1.5 million bachelors degrees are awarded annually in the US. ${ }^{2}$ About 70,000 are Engineering degrees, and about 15,000 are Engineering Technology (ET) degrees and Technician degrees. The number of Mechanical, Civil, and Construction Engineering Technology graduates is less than 2,000 per year, so the market for algebra-based Strength of Materials textbooks for ET is a small fraction of the market for calculus-based Engineering textbooks. The few ET Strength books are technically excellent, but are not always easy for undergraduates to understand.

My students complain that the explanations in many Engineering Technology textbooks are too theoretical, too wordy, and too difficult to understand. They also complain about the lack of complete unit conversions in example problems, and inconsistent use of symbols between related courses. For example, some authors use $s_{n}, s_{s}$, and $e$ for normal stress, shear stress, and strain, instead of the standard Greek symbols $\sigma, \tau$, and $\varepsilon$. This use of Latin characters with multiple subscripts confuses students because the Greek symbols are used in textbooks for other courses, and because capital $S$ is used for section modulus later in this course. Students have trouble distinguishing between $s$ and $S$ on the chalkboard during lectures (and in their notes).

My students also complain about the high cost of textbooks. In the last 30 years, textbook costs have risen about twice as fast as inflation, so this is a reasonable complaint. 
To address these issues, I decided to use my first sabbatical to write a tailor-made textbook for my students. When I went to college in the 1980s, printed textbooks were the only option. These books were updated once every 4 to 10 years based on input from experts in the field, typically other college professors. Today, the internet offers another option: low-cost or free e-books available online which can be revised more frequently than printed books. As an added benefit, color is free on electronic displays (laptops, cell phones, pad devices). For all of these reasons, I decided to provide the textbook to the students as a pdf file, available for free on the university's website. $^{3}$

\section{The Writing Process}

Early in the writing process I looked for software that is inexpensive, easy to learn and use, does not crash frequently with large files, handles graphics and equations easily, and produces a reasonably small pdf file (less than $4 \mathrm{MB}$ ) for the finished textbook.

Table 2: Software comparison

\begin{tabular}{|c|c|c|c|c|}
\hline Software & Advantages & Disadvantages & Equations & Graphics \\
\hline $\begin{array}{l}\text { MS Word } \\
\text { (Microsoft } \\
\text { Corp.) }\end{array}$ & Easy to learn & $\begin{array}{l}\text { Crashes with large } \\
\text { files; produces very } \\
\text { large pdf output file; } \\
\text { MathType equation } \\
\text { formatting too } \\
\text { automatic }\end{array}$ & MathType & $\begin{array}{l}\text { Images are bitmaps } \\
\text { (insufficient } \\
\text { resolution in pdf file) }\end{array}$ \\
\hline $\begin{array}{l}\text { Pages } \\
\text { Apple Inc.) }\end{array}$ & Easy to learn & $\begin{array}{l}\text { Limited user control } \\
\text { in formatting graphs; } \\
\text { MathType equation } \\
\text { formatting too } \\
\text { automatic }\end{array}$ & MathType & Primitive \\
\hline $\begin{array}{l}\text { Scrivener } \\
\text { (Literature \& } \\
\text { Latte) }\end{array}$ & $\begin{array}{l}\text { Great for all-text } \\
\text { documents such as } \\
\text { novels; master } \\
\text { document links } \\
\text { individual chapter } \\
\text { files }\end{array}$ & $\begin{array}{l}\text { No page layout } \\
\text { features for images, } \\
\text { tables, equations } \\
\text { (output must be } \\
\text { formatted by } \\
\text { additional software } \\
\text { such as MS Word) }\end{array}$ & MathType & None \\
\hline $\begin{array}{l}\text { Apache Open } \\
\text { Office } \\
\text { (Apache } \\
\text { Software } \\
\text { Foundation) }\end{array}$ & $\begin{array}{l}\text { Free; does not crash } \\
\text { with large files; } \\
\text { master document } \\
\text { links individual } \\
\text { chapter files; file } \\
\text { opens at last saved } \\
\text { place, not top of the } \\
\text { document; pdf output } \\
\text { very small. }\end{array}$ & $\begin{array}{l}\text { Equations unreadable } \\
\text { if there are too many } \\
\text { in the document } \\
\text { (must split document } \\
\text { into multiple files) } \\
\text { Need to learn } \\
\text { equation software }\end{array}$ & $\begin{array}{l}\text { Open Office } \\
\text { Math (similar } \\
\text { to LaTex) }\end{array}$ & $\begin{array}{l}\text { Includes easy-to-learn } \\
\text { graphics software } \\
\text { with high resolution } \\
\text { output }\end{array}$ \\
\hline
\end{tabular}

Software cost was not really an issue because of academic discounts. Crash-resistance, the ability to produce high-resolution diagrams, formatting control of equations, and final pdf file size were the main criteria. 
Apache Open Office met the needs best, and had the least significant disadvantages. Graphics are outstanding, equations are easier to create with vertical lines separating unit conversions, and the software is less prone to crashing than MS Word.

The next step in planning the book was to select a common set of symbols. All Strength textbooks use $E$ for Young's modulus, but there is less agreement between textbook authors for quantities such as normal stress, shear stress, radius of gyration, and other terms listed in Table 3. I tended to select the most recently used symbols because students are more likely to see them in other courses such as Statics, Materials I and Machine Elements.

Table 3: Symbols used in various Strength of Materials textbooks. The Engineering Technology (ET) texts are mostly algebra-based, while the Engineering (E) texts use algebra and calculus.

\begin{tabular}{|c|c|c|c|c|c|c|c|c|c|c|c|c|c|}
\hline Textbook: & $\mathbf{A}^{4}$ & $\mathbf{B}^{5}$ & $\mathrm{C}^{6}$ & $\mathbf{D}^{7}$ & $\mathbf{E}^{8}$ & $\mathbf{F}^{9}$ & $G^{10}$ & $\overline{H^{11}}$ & $I^{12}$ & $\mathbf{J}^{13}$ & $\mathbf{K}^{14}$ & $\mathbf{L}^{15}$ & $\mathbf{M}^{16}$ \\
\hline $1^{\text {st }}$ edition & '08 & '07 & '01 & '91 & '88 & '85 & '81 & 76 & '69 & '53 & 49 & 47 & '30 \\
\hline Edition used & '08 & '07 & '04 & '09 & '88 & '97 & '06 & 76 & '69 & '53 & 49 & '62 & 56 \\
\hline ET or Engineering & $\mathrm{E}$ & $\mathrm{E}$ & E & ET & ET & ET & E & $\mathrm{E}$ & ET & $\mathrm{E}$ & E & ET & $\mathrm{E}$ \\
\hline Normal stress & $\sigma$ & $\sigma$ & $\sigma$ & $\mathrm{s}$ & $\sigma$ & $\bar{\sigma}$ & $\sigma$ & $\sigma$ & $\sigma$ & $\mathrm{S}$ & $\mathrm{s}$ & $\mathrm{s}$ & $\sigma$ \\
\hline Shear stress & $\tau$ & $\tau$ & $\tau$ & $\mathrm{S}_{\mathrm{s}}$ & $\tau$ & $\tau$ & $\tau$ & $\tau$ & $\tau$ & $\mathrm{S}_{\mathrm{s}}$ & $\mathrm{S}_{\mathrm{s}}$ & $\mathrm{S}_{\mathrm{s}}$ & $\tau$ \\
\hline Strain & $\varepsilon$ & $\varepsilon$ & $\varepsilon$ & $\mathrm{e}$ & $\varepsilon$ & $\varepsilon$ & $\varepsilon$ & $\varepsilon$ & $\varepsilon$ & $\varepsilon$ & $\varepsilon$ & $\varepsilon$ & $\varepsilon$ \\
\hline Poisson's ratio & $v$ & $v$ & $v$ & $\mu$ & $\mu$ & $\mu$ & $v$ & $\mu$ & $\mu$ & $\mu$ & $\mu$ & & $\mu$ \\
\hline Point load & $\mathrm{P}$ & $\mathrm{P}$ & $\mathrm{P}$ & $\mathrm{P}$ & $\bar{F}$ & $\mathrm{P}$ & $\mathrm{P}$ & $\mathrm{F}$ & $\mathrm{P}$ & $\mathrm{P}$ & $\mathrm{P}$ & $\mathrm{P}$ & $\mathrm{P}$ \\
\hline $\begin{array}{l}\text { Stress } \\
\text { concentration }\end{array}$ & $\mathrm{K}$ & $\mathrm{K}$ & $\mathrm{K}$ & $\mathrm{k}$ & $\mathrm{k}$ & $\mathrm{K}$ & $\mathrm{K}$ & $\mathrm{K}_{\mathrm{t}}$ & & & & & $\mathrm{k}$ \\
\hline Radius of gyration & & $\mathrm{k}$ & $\mathrm{r}$ & $\mathrm{r}$ & $\mathrm{q}$ & & $\mathrm{r}$ & $\mathrm{k}$ & $\mathrm{k}$ & & $\mathrm{k}$ & & $\mathrm{k}$ \\
\hline Section modulus & & & & $\mathrm{S}$ & $\mathrm{Z}$ & $\mathrm{S}$ & & $\mathrm{Z}$ & $Z$ & & $Z$ & & \\
\hline $\begin{array}{l}\text { Plastic section } \\
\text { modulus }\end{array}$ & & & & $\mathrm{Z}$ & & $\mathrm{Z}$ & & & & & & & \\
\hline
\end{tabular}

The textbooks referenced in Table 3 were a great resource for selecting topics and deciding on their order. Most textbooks in this field intentionally contain more information than can be effectively covered in one semester, so the instructor can tailor the course to the needs of the students by including or dropping particular sections. Since I was writing a book for a specific audience at one institution, I eliminated extra topics that my students do not need (such as the Moment-Area theorem), and added a topic that my Architectural and Civil Engineering Technology students are deficient in: unit conversions.

The table of contents on the next page shows how the book starts with a chapter on the FactorLabel Method of Unit Conversion, then moves through the easier Strength topics such as thermal expansion, pressure vessels, and bolted joints. Students develop problem-solving techniques and practice unit conversions with easy problems. These skills help students with subsequent harder topics such as beam analysis and Mohr's circle. 
Table 4: Table of contents of the textbook.

\begin{tabular}{|c|c|}
\hline Preface & Allowable Load \\
\hline Purpose of the Book & Chapter 10: Beam Deflection \\
\hline Editors & Radius of Curvature \\
\hline Terminology & The Formula Method for Simple Cases \\
\hline Definitions & Formula Method Hints \\
\hline Chapter 1: Introduction to Strength of Materials & The Formula Method for Complex Cases: \\
\hline What is Strength of Materials? & Superposition \\
\hline The Factor-Label Method of Unit Conversion & Chapter 11: Beam Design \\
\hline Chapter 2: Stress and Strain & Wide-Flange Steel Beam Design in Six Easy Steps \\
\hline Normal Stress and Strain & Timber Beam Design in Six Easy Steps \\
\hline Sign Convention & Chapter 12: Combined Stresses \\
\hline Shear Stress and Strain & Tension + Bending \\
\hline Chapter 3: Poisson's Ratio and Thermal Expansion & Bending in Two Directions \\
\hline Poisson's Ratio & Eccentric Loading \\
\hline Thermal Expansion and Thermal Stress & Chapter 13: Statically Indeterminate Beams \\
\hline Chapter 4: Pressure Vessels and Stress Concentrations & Defining Determinate and Indeterminate Beams \\
\hline Thin-Walled Pressure Vessels & Method of Superposition \\
\hline Stress Concentration in Tension & Chapter 14: Buckling of Columns \\
\hline Chapter 5: Bolted and Welded Joints & Types of Columns \\
\hline Bolted Lap Joints Loaded in Tension & Ideal Slender Columns \\
\hline Welded Lap Joints & Structural Steel Columns \\
\hline Chapter 6: Properties of Areas & Steel Machine Parts \\
\hline Dimensions and Area & Chapter 15: Visualizing Stress and Strain \\
\hline Centroid and Centroidal Axes & Measuring Stress \\
\hline Moment of Inertia of a Rectangle & Stress at the Base of a Short Block \\
\hline Compound Beams Sharing a Centroidal Axis & Mohr's Circle \\
\hline Hollow Beams Sharing a Centroidal Axis & Bibliography \\
\hline The Transfer Formula & Textbooks \\
\hline Compound Beams With Different Neutral Axes & Other Reading Material \\
\hline Hollow Beams With Different Neutral Axes & Appendix A: Units \\
\hline When the Transfer Formula is Not Needed & SI System of Units and Prefixes \\
\hline Radius of Gyration & US Customary System of Units and Prefixes \\
\hline Polar Moment of Inertia & Conversions Between Unit Systems \\
\hline Chapter 7: Torsion in Round Shafts & Appendix B: Materials Properties \\
\hline Shear Stress in a Round Shaft & Metals, Concrete, \& Stone \\
\hline Angle of Twist in a Round Shaft & Appendix C: Properties of Areas \\
\hline Stress Concentration in Torsion & Center of Gravity, Area, Moment of Inertia, and \\
\hline Chapter 8: Beam Reactions, Shear Diagrams, and & Radius of Gyration \\
\hline Moment Diagrams & Appendix D: Properties of Steel Beams and Pipes \\
\hline Loads on Beams & $W$-beams \\
\hline Reactions for Simply-Supported Simple Beams & Steel Pipes \\
\hline Reactions for Overhanging and Cantilever Beams & Copper Tubing \\
\hline Shear Diagrams & Appendix E: Mechanical and Dimensional Properties of \\
\hline Moment Diagrams & Wood \\
\hline Chapter 9: Stresses in Beams & Mechanical Properties of Air-Dried Boards and \\
\hline Bending Stress in Beams & Timber \\
\hline Bending Stress in Steel Beams & Softwood Lumber and Timber Sizes \\
\hline Shear Stress in Beams & Appendix F: Beam Equations \\
\hline & Index \\
\hline
\end{tabular}


The best Strength textbooks include a list of terminology (with typical units), either at the beginning of the book or in an appendix. I added a set of definitions, because my students tend to forget the meanings of the terms.

\section{Algebraic Problems}

In conversation and by their work, my students tell me they want help with algebra skills, unit conversions, and problem-solving approaches. The new book contains problems requiring an algebraic answer as well as traditional problems requiring a numerical answer. For example, here are problems for the chapter on stress and strain for the Spring 2013 semester:

1. Calculate the strain in a $2 \frac{1}{2}$ in. long rubber band that is stretched to a total length of $4 \frac{1}{4} \mathrm{in}$. [\%]

2. Calculate the strain in a $12 \mathrm{~m}$ long bar if it stretches $5 \mathrm{~mm}$. [unitless, decimal number]

3. A round rod is loaded under a tensile load $P$. Using $\sigma=\frac{P}{A}$, develop an algebraic equation for calculating the diameter, $d$, such that $d$ is a function of $P$ and $\sigma$.

4. Use the previous equation to find the diameter of a rod that will support a tensile load of 4 kips if the allowable stress is 36,000 psi. [in.]

5. Using $\delta=\frac{P L}{A E}$, develop an algebraic equation for calculating the diameter, $d$, of a round rod such that $d$ is a function of $P, L, \delta$, and $E$.

6. Use the previous equation to find the diameter of a $6 \mathrm{~m}$ long rod that will support a tensile load of $130 \mathrm{kN}$ and stretch no more than $2.5 \mathrm{~cm}$, if Young's modulus is $110 \mathrm{GPa}$. [mm]

7. A 25 ton stamping press is used for punching circles out of sheet metal with a shear strength of 22 ksi and a thickness of 0.032 in. What is the largest diameter circle that the press can produce with a flat punch? [in.]

Problems 1, 2, 4, 6, and 7 are "plug \& chug" problems that students prefer; however, in order to solve problems 4 and 6, students must first derive algebraic expressions in problems 3 and 5.

The Factor-Label Method of Unit Conversion is emphasized from the first chapter, and is used in all example problems.

\section{Refer to Older Books...but Check Sources}

I found that other textbooks are a good guide for content, difficulty level, ways to explain topics, and layout. For example, the best texts display illustrations on the same page as the relevant text, they include an easy-to-find list of terminology, they list the key equations at the end of each chapter, and they have good indices. Unfortunately, some authors borrow content from older textbooks without verifying accuracy. For example, some Strength textbooks discuss wrought iron and its use in water pipes as if it were a current material; in fact, wrought iron has not been used for water pipes since the early $20^{\text {th }}$ century. The last wrought iron factory in the world closed in 1973. 


\section{Selection of Topics Requiring Extra Focus}

Some topics are harder for students to learn, and therefore need more explanation and more examples. I looked at the average grades over 7 semesters on the various homework assignments and ranked them in Table 5. The most troublesome three topics differ from the rest in that they require multistep problem-solving techniques; the easiest topics require simple one-step calculations.

Table 5: Average grade from Fall 2008 to Fall 2011 for each homework topic, sorted from low to high grade. The lowest three grades were on topics requiring a multistep problem-solving technique.

\begin{tabular}{|c|c|}
\hline Topic & $\begin{array}{c}\text { Average grade } \\
\text { over } 7 \text { semesters }\end{array}$ \\
\hline Shear \& moment diagrams & 50 \\
\hline Moment of inertia of a compound shape & 57 \\
\hline Beam design & 59 \\
\hline Stress \& strain & 60 \\
\hline Elongation / thermal expansion & 62 \\
\hline Bending stress in beams & 62 \\
\hline Combined stresses / short blocks \#1 & 65 \\
\hline Bending \& shear stresses in beams & 65 \\
\hline Combined stress cases & 66 \\
\hline Bolted connections & 67 \\
\hline Columns & 67 \\
\hline Shear stress in beams & 68 \\
\hline Beam reactions / shear diagrams & 69 \\
\hline Statically indeterminate beams & 70 \\
\hline Formula Method & 71 \\
\hline Columns & 71 \\
\hline Welded connections & 73 \\
\hline Torque & 74 \\
\hline Combined stresses / short blocks \#2 & 78 \\
\hline Torsional stresses & 78 \\
\hline Pressure vessels & 78 \\
\hline Stress concentrations & 79 \\
\hline Beam deflection with the Formula Method & 81 \\
\hline
\end{tabular}

Finding the moment of inertia of a compound shape requires the student to build a diagram and calculate many dimensions and intermediate quantities. In the classroom, the professor builds the diagram on the board in real time, like a movie; however, the finished product in a student's notebook only shows the final frame of the movie. A better way to teach this topic is to show the students each movie frame. I created a study guide ${ }^{17}$ for calculating moment of inertia "in 10 easy steps", posting it on the web. In the study guide, the student can follow a frame-by-frame solution for each example problem. I also created study guides for drawing shear and moment diagrams, and for beam analysis; these three guides became the core of the new textbook. 
The method for drawing a shear diagram is shown below in 6 diagrams. Accompanying text and equations are aligned with each diagram. Each image builds on the previous frame, until the shear diagram is complete.

We can sketch $V$ as a function of location along the beam using below the load diagram wherever the applied loads and reaction indicating zero shear load. Next, draw the value of $V$ along the

Step 1 Starting at the left side of the shear diagram, go up $15 \mathrm{kI}$

Step 2 There are no additional loads on the beam until you get $\mathrm{t}$

Step 3 The applied load at the midspan is $30 \mathrm{kN}$ downwards, th

$$
15 \mathrm{kN}-30 \mathrm{kN}=-15 \mathrm{kN}
$$

Step 4 There are no additional loads on the beam until you get $t$

Step 5 At point B, the reaction force $R_{B}=15 \mathrm{kN}$ upwards, there don't get to 0 , you know you hadd a nside Oomeplace.

Finish the shear diagram by shading the areas between your significant points (anywhere the shear line changes direction

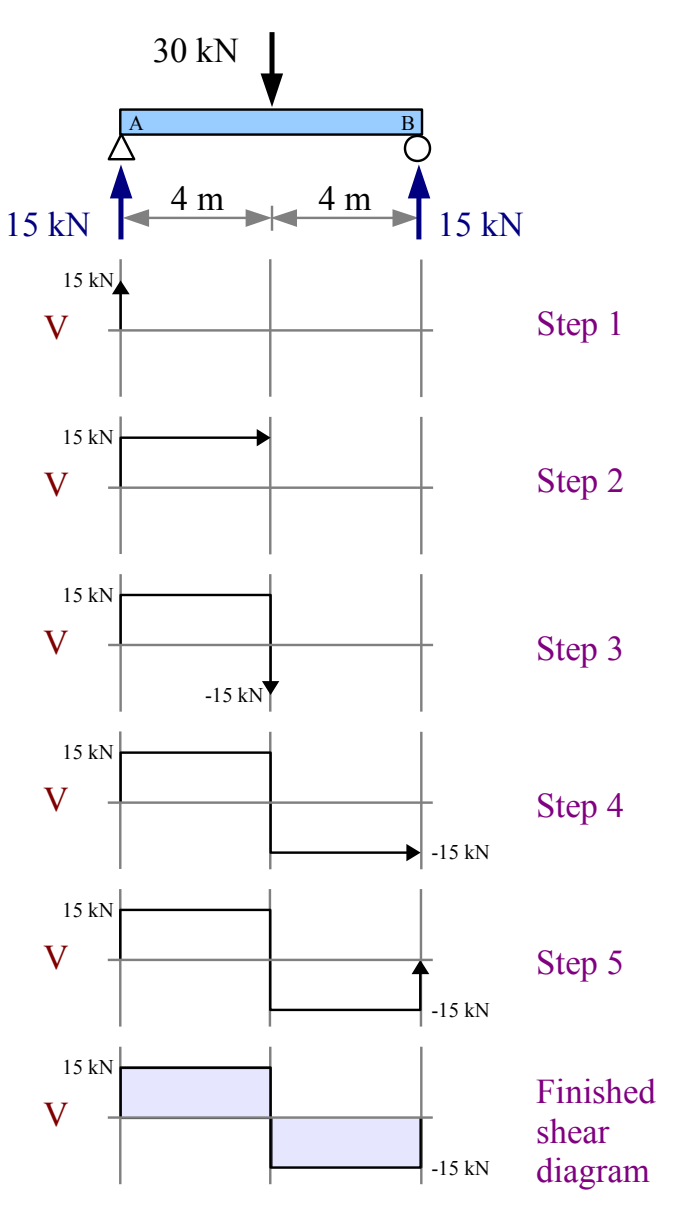
absolute value of shear load, $|V|_{\max }$, to calculate the maximum shear stress in the beam.

Since shear and moment diagrams give students more trouble than any other topic, the shear and moment chapter includes 22 fully worked examples.

Notice the use of color in the shear diagram example. Color is used throughout (on $87 \%$ of the pages) to differentiate between dimensions lines and construction lines, between applied forces and reaction forces, between solid and hollow sections, between applied loads and beam weights. I avoided mixing green and red colors in the same diagram, and asked if any colorblind students to tell me if any color combinations caused trouble; no student reported any problems. Some students chose to print the book in color because color printing is widely available and cheap; others brought laptops or electronic pad devices to class. 


\section{Editing Assistance from Students}

I awarded extra credit points to students who submitted recommendations for improving the textbook. Of the 25 students who took the final exam, 6 submitted recommendations...a 24\% response rate. This rate is substantially lower than the extra-credit participation in the previous two semesters, when students were asked to recommend changes to study guides posted online. The response rate on the study guides was 50\% and 55\% in Fall 2011 and Spring 2011, respectively.

Textbook feedback was specific and actionable: every comment referred to a particular issue on a particular page of the book. Most comments regarded typographical errors, but some discussed clarity. For example, the problem set referred to the "tabular method" of solving moment of inertia problems of compound shapes. Although tables were used in the method discussed in the textbook, I never used the term "tabular method" in the textbook, confusing a student who did not understand the term.

One student suggested:

Include a few more examples in Chapter 11 on beam design where when adding in the weight of the beam the max. moments are not at the same spot for both point load and weight of the beam.

This recommendation was easy to implement by changing an example problem. Another student remarked:

I found Chapter 15 very confusing. I think the 6 steps for Mohr's circle would be better if you have a list of points defined and not associated with the concept of the three sine waves from page 5. It should be separated from the previous material, and then it would better flow into examples 1, 2, and 3. This would be a lot clearer on how to go thru the steps. I made the homework way harder than it was, trying to follow the chapter.

This student occasionally missed lectures because of his job, so he often relied solely on the textbook to help him solve homework problems...this may have been the case with the Mohr's circle problems. Students who attended the lectures more regularly did very well on this particular assignment. I need to review the chapter and my lecture notes, and make sure the explanation in the textbook is written more clearly.

\section{Assessment and Lessons Learned}

Summarizing, the goals of this book are:

- Free or low-cost distribution of a file smaller than $4 \mathrm{MB}$ over the internet

- Frequent revisions based on student input

- Concise explanations

- Examples with complete unit conversions

- Standard Greek symbols for stress and strain

- Problems requiring algebraic answers as well as problems requiring numerical answers

- Problems requiring answers in sentences to show reasoning and understanding of the topics

- Lower failure rate in Strength of Materials classes through better learning 
The first seven goals were met: the $2 \mathrm{MB}$ pdf file is freely available online; the book is revised every semester; explanations are clearly concise because the book is a fraction of the length of a conventional textbook; all examples have complete unit conversions and use standard symbols; about $10 \%$ of the problems are algebra-only.

Given the low participation rate in the extra-credit option for submitting editing suggestions, I have added a required question to every chapter-ending homework assignment:

Describe at least one improvement you would make to this chapter to make it more understandable.

By phrasing the question this way, I am receiving more useful feedback in the Spring 2013 section. As of the end of February 2013 , the response rate is $86 \%$.

The final and most important goal, reducing the repeat rate in this class through better learning, was not achieved. I had hoped to reduce the repeat rate to $10 \%$ or less. In this first semester of using the new book the repeat rate was $24 \%$...no different than recent semesters. Four students failed the course outright; none of these four showed up for the final exam.

At the end of the semester, students complete a course survey. One question asks the students to rate the textbook on a scale of 1 to 4: poor, fair, good, and excellent. Table 6 shows that the average evaluation score from 15 semesters of classes rose from 3.01 out of 4 to 3.67 out of 4...the highest score I've ever seen on this question in any course. What is not clear is the reason for the increase...is it because students like the electronic format, because the book was tailormade for them, or because it was free?

Table 6: Student evaluation score on question "The textbook: 4) Excellent, 3) Good, 2) Fair, 1) Poor" in my section of Strength of Materials each semester.

\begin{tabular}{llllllllllllllll}
\hline F03 & S04 & F04 & S05 & S06 & S07 & F07 & S08 & F08 & S09 & F09 & S10 & F10 & S11 & F11 & F12 \\
\hline 2.80 & 3.08 & 3.17 & 3.33 & 3.00 & 2.95 & 3.07 & 2.92 & 2.88 & 3.10 & 2.62 & 3.30 & 3.00 & 2.94 & 3.00 & 3.67 \\
\hline
\end{tabular}

\section{Further Work}

Tailor-made textbooks available for free as pdf files can have a positive impact on student learning and student satisfaction. Out-of-print textbooks are already available online, often on their authors' websites. The next step is to create a clearinghouse for free textbooks...perhaps ASEE could provide this as a service to its members. In the meantime, I plan to develop another pdf textbook for one of my courses following 10 easy steps:

1. Select a software package for writing and diagrams

2. Select symbols, referring to other textbooks as guides for currently used symbols

3. Use other textbooks as references, but verify facts - avoid propagating errors

4. Decide on the order of presentation, and create a list of chapters

5. Review grades from previous semesters to select topics requiring extra focus

6. Write the chapters (the most time-consuming step)

7. Use step-by-step illustrated examples for multistep solution methods

8. Write a new set of homework problems each semester

9. Post the textbook as a pdf

10. Solicit feedback from students for improving the next version of the textbook 
${ }^{1}$ Data from grade distribution reports, available at http://new.ipfw.edu/microsites/university-archives/administrativearchives/

${ }^{2}$ Data from 2007-2008. Updated numbers are available online in the Digest of Educational Statistics, published by the National Center for Educational Statistics, U.S. Department of Education.

${ }^{3} \mathrm{http}: / /$ www.etcs.ipfw.edu/ dupenb/ET_200/Applied\%20Str\%20of\%20Mat\%20for\%20ET\%20v3\%20Jan\%202013.pdf

${ }^{4}$ Vable, Intermediate Mechanics of Materials. 2008.

${ }^{5}$ Riley, Sturges, \& Morris, Mechanics of Materials, $6^{\text {th }}$ ed. Wiley, 2007.

${ }^{6}$ R.C. Hibbeler, Statics and Mechanics of Materials, $3^{\text {rd }}$ ed. Pearson Prentice Hall, 2010.

${ }^{7}$ Limbrunner \& Spiegel, Applied Statics and Strength of Materials, $5^{\text {th }}$ ed. 2009.

${ }^{8}$ Wolf, Statics and Strength of Materials: A Parallel Approach to Understanding Structures. 1988.

${ }^{9}$ Cheng, Statics and Strength of Materials, $2^{\text {nd }}$ ed. 1997.

${ }^{10}$ Beer, Johnston, \& DeWolf, Mechanics of Materials, $4^{\text {th }}$ ed. 2006.

${ }^{11}$ Shigley, Applied Mechanics of Materials. 1976.

${ }^{12}$ Eckardt, Strength of Materials. 1969.

${ }^{13}$ Fairman \& Cutshall, Mechanics of Materials. 1953.

${ }^{14}$ J.P. Den Hartog, Strength of Materials. McGraw-Hill, 1969 (republished by Dover, 1977.

${ }^{15}$ Jensen, Statics and Strength of Materials. 1962.

${ }^{16}$ Stephen Timoshenko, Strength of Materials Part II: Advanced Theory and Problems, $3^{\text {rd }}$ ed. 1956.

${ }^{17}$ Barry Dupen, "Designing User-Friendly Handouts for Mechanics Courses", The Technology Interface, Vol. 7 No. 1, Fall 2006, ISSN 1523-9926. 